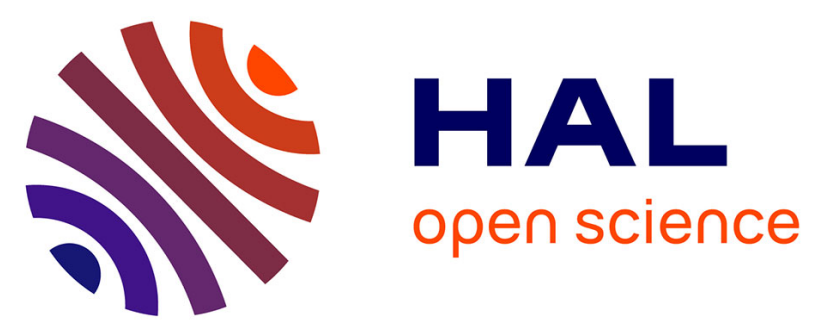

\title{
Parameterizing the binding properties of dissolved organic matter with default values skews the prediction of copper solution speciation and ecotoxicity in soil
}

Tanalou Djae, Matthieu N Bravin, Cédric Garnier, Emmanuel Doelsch

\section{- To cite this version:}

Tanalou Djae, Matthieu N Bravin, Cédric Garnier, Emmanuel Doelsch. Parameterizing the binding properties of dissolved organic matter with default values skews the prediction of copper solution speciation and ecotoxicity in soil. Environmental Toxicology and Chemistry, 2016, 36, pp.898 - 905. 10.1002/etc. 3622 . hal-03547960

\author{
HAL Id: hal-03547960 \\ https://hal.science/hal-03547960
}

Submitted on 29 Jan 2022

HAL is a multi-disciplinary open access archive for the deposit and dissemination of scientific research documents, whether they are published or not. The documents may come from teaching and research institutions in France or abroad, or from public or private research centers.
L'archive ouverte pluridisciplinaire HAL, est destinée au dépôt et à la diffusion de documents scientifiques de niveau recherche, publiés ou non, émanant des établissements d'enseignement et de recherche français ou étrangers, des laboratoires publics ou privés. 


\title{
PARAMETERIZING THE BINDING PROPERTIES OF DISSOLVED ORGANIC MATTER WITH DEFAULT VALUES SKEWS THE PREDICTION OF COPPER SOLUTION SPECIATION AND ECOTOXICITY IN SOIL
}

\author{
Tanalou Duae, $\dagger \ddagger \S \|$ Matthieu N. Bravin,* $\|$ Cédric Garnier, $\S$ and Emmanuel Doelsch $\ddagger$ \\ $\dagger$ ADEME, Angers, France \\ $\ddagger$ †IRAD, UPR Recyclage et Risque, Montpellier, France \\ $\S$ Université de Toulon, PROTEE, La Garde, France \\ ICIRAD, UPR Recyclage et Risque, Saint-Denis, Réunion, France
}

(Submitted 7 July 2016; Returned for Revision 6 September 2016; Accepted 12 September 2016)

\begin{abstract}
Parameterizing speciation models by setting the percentage of dissolved organic matter (DOM) that is reactive (\% r-DOM) toward metal cations at a single $65 \%$ default value is very common in predictive ecotoxicology. The authors tested this practice by comparing the free copper activity $\left(\mathrm{pCu}^{2+}=-\log _{10}\left[\mathrm{Cu}^{2+}\right]\right)$ measured in 55 soil sample solutions with $\mathrm{pCu}^{2+}$ predicted with the Windermere humic aqueous model (WHAM) parameterized by default. Predictions of $\mathrm{Cu}$ toxicity to soil organisms based on measured or predicted $\mathrm{pCu}^{2+}$ were also compared. Default WHAM parameterization substantially skewed the prediction of measured $\mathrm{pCu}^{2+}$ by up to $2.7 \mathrm{pCu}^{2+}$ units (root mean square residual $=0.75-1.3$ ) and subsequently the prediction of $\mathrm{Cu}$ toxicity for microbial functions, invertebrates, and plants by up to $36 \%, 45 \%$, and $59 \%$ (root mean square residuals $\leq 9 \%, 11 \%$, and $17 \%$ ), respectively. Reparametrizing WHAM by optimizing the 2 DOM binding properties (i.e., $\%$ r-DOM and the Cu complexation constant) within a physically realistic value range much improved the prediction of measured $\mathrm{pCu}^{2+}$ (root mean square residual $=0.14-0.25$ ). Accordingly, this WHAM parameterization successfully predicted $\mathrm{Cu}$ toxicity for microbial functions, invertebrates, and plants (root mean square residual $\leq 3.4 \%$, $4.4 \%$, and $5.8 \%$, respectively). Thus, it is essential to account for the real heterogeneity in DOM binding properties for relatively accurate prediction of $\mathrm{Cu}$ speciation in soil solution and $\mathrm{Cu}$ toxic effects on soil organisms. Environ Toxicol Chem 2016;9999:1-8. (C) 2016 SETAC
\end{abstract}

Keywords: Trace elements Dose-response modeling Complexation Fulvic acid Windermere humic aqueous model (WHAM)

\section{INTRODUCTION}

Speciation in solution is unequivocally considered to be an effective way to estimate the bioavailability and toxicity of metal cations to soil organisms. Among metal species in solution, free metal cations are considered to be the main bioavailable and toxic species for soil organisms [1,2]. Accordingly, determination of the activity of free metal cations in soil solution is critical for most recently developed ecotoxicological models [3-5].

The most direct approach to estimate the activity of free metal cations in soil solution is to determine it analytically. Many analytical techniques, such as the Donnan membrane technique and electrochemical methods based on voltammetry or potentiometry, are still used to measure the activity of metal cations in soil solution [6]. All of these techniques have, however, specific analytical drawbacks, such as being timeconsuming, not directly related to the free metal form, and not sensitive enough to deal with the full range of the environmentally relevant activities of free metal cations usually found in real soil solutions.

The activity of free metal cations in soil solution may also be estimated by modeling. Speciation models work with 1) input parameters that can be measured routinely in soil solutions, such as $\mathrm{pH}$ and total metal cation and dissolved organic matter (DOM) concentrations, and 2) databases describing metal cation

This article includes online-only Supplemental Data.

* Address correspondence to matthieu.bravin@cirad.fr

Published online 14 September 2016 in Wiley Online Library

(wileyonlinelibrary.com).

DOI: $10.1002 /$ etc. 3622 binding with inorganic ligands and DOM. Because of the high affinity of DOM for metal cations and the heterogeneity and complexity of the molecular structure of DOM, the modeling of metal cation binding with DOM is highly challenging [7].

The humic ion-binding model included in the Windermere humic aqueous model (WHAM) [8] and the nonideal competitive adsorption (NICA)-Donnan model $[9,10]$ are currently the 2 models most widely used for simulating metal cation binding with DOM and consequently for estimating free metal cation activity. Because fulvic acids are among the most abundant DOM components in soil and particularly reactive toward metal cations [11-13], these 2 models similarly describe the binding properties of DOM as those of a reference fulvic acid parameterized specifically in each model. Beyond the analytically determined input parameters (e.g., $\mathrm{pH}$, metal cation, and DOM concentrations), the activity of free metal cations is thus estimated in WHAM and the NICA-Donnan model by theoretically adjusting the percentage of DOM reactive toward metal cations (hereafter referred to as \% r-DOM), corresponding to the fraction of DOM assumed to have the same reactivity toward metal cations as the defined reference fulvic acid, with the remaining DOM being considered inert. The free metal cation activity could also be successfully predicted by optimizing the binding constant of metal cations of the reference fulvic acid. However, model optimization by adjusting the \% r-DOM is a more generic and practical approach [14-17].

Early studies focused on reactive DOM in natural waters revealed that the \% r-DOM ranged from $30 \%$ to $120 \%$ but that the bulk of it was within the $40 \%$ to $80 \%$ range $[14,15]$. 
Vulkan et al. [18] predicted $\mathrm{Cu}^{2+}$ activity in the solution of 22 soil samples from 4 areas, with a difference between measured and calculated values below \pm 0.5 free copper activity $\left(\mathrm{pCu}^{2+}\right.$; $-\log _{10}\left[\mathrm{Cu}^{2+}\right]$ ) units in $82 \%$ of the samples when the \% r-DOM was set at a single value (i.e., 69\%). Accordingly, in WHAM and the NICA-Donnan model, the \% r-DOM is thereafter very often set at the single default value of $65 \%$ to predict the activity of free metal cations in soil solutions $[19,20]$ and subsequently to predict the toxic effect of metal cations on soil organisms [3,4,21-24].

Nolan et al. [25], however, found that WHAM parameterization with a $\%$ r-DOM set at $100 \%$ or $70 \%$ poorly fit the measured activities of $\mathrm{Cu}^{2+}$ and $\mathrm{Pb}^{2+}$ in the solution of 25 soil samples. This result suggests that the $\%$ r-DOM variability in soil solutions could be much greater than previously expected. In agreement, Amery et al. [17] more recently estimated that the $\%$ r-DOM ranged from $28 \%$ to $152 \%$ in soil solutions collected over time in a soil profile. De Schamphelaere et al. [16] also showed that accounting for the variability in the $\%$ r-DOM when estimating $\mathrm{Cu}^{2+}$ activity in solution improved the prediction of $\mathrm{Cu}$ toxicity to Daphnia magna. Accordingly, the very common practice of setting \% r-DOM at a single $65 \%$ default value is per se an approximation. The extent to which this approximation may skew the prediction of metal cation speciation in solution and toxicity to soil organisms is highly questionable.

To test this very common practice, we compared 1) $\mathrm{Cu}^{2+}$ activity measured in soil solutions with $\mathrm{Cu}^{2+}$ activity predicted by modeling using default settings and 2) the prediction of $\mathrm{Cu}$ toxicity to soil organisms calculated from $\mathrm{Cu}^{2+}$ activity measured with that calculated from $\mathrm{Cu}^{2+}$ activity predicted by modeling using default settings. The present study was applied to 55 soil samples exhibiting a very wide range of physicochemical properties. Finally, uncertainty and sensitivity analyses were performed to highlight the impact on predicted $\mathrm{Cu}^{2+}$ activity of 1 ) analytical errors in measured input parameters (i.e., $\mathrm{pH}$, total $\mathrm{Cu}$ concentrations, and DOM concentration), and 2) the variability in parameters other than \% r-DOM that are usually set at a single default value (i.e., $\mathrm{Cu}$ binding constant of DOM and the solubility products of $\mathrm{Al}[\mathrm{OH}]_{3}$ and $\mathrm{Fe}[\mathrm{OH}]_{3}$ ).

\section{MATERIALS AND METHODS}

\section{Soil characteristics and incubation}

Fifty-five soil samples were collected from agricultural and forest areas in mainland France $(n=46)$ and the 2 French tropical islands of Réunion $(n=7)$ and New Caledonia $(n=2)$. Soil samples were air-dried and sieved to $2 \mathrm{~mm}$. The physicochemical properties of the soil samples were then determined according to French and international standardized procedures. Soil samples were selected to encompass a broad range of physicochemical soil characteristics and different origins of trace elements present (Table 1; Supplemental Data, Tables S1 and S2).

The 55 soil samples were incubated ex situ using the RHIZOtest experimental device. The RHIZOtest is a standardized plant-based test designed to evaluate the bioavailability of trace elements to soil-grown plants [26,27]. Briefly, cabbage (Brassica oleracea), tall fescue (Festuca arundinacea), and tomato (Lycopersicon esculentum) were grown in hydroponic conditions for $14 \mathrm{~d}$. At the same time, the 55 soil samples were incubated at $70 \%$ of their water holding capacity with a nutrient solution consisting of $0.05 \mathrm{mM} \mathrm{KH}{ }_{2} \mathrm{PO}_{4}, 2 \mathrm{mM} \mathrm{KNO} 3,1 \mathrm{mM}$ $\mathrm{MgSO}_{4}$, and $2 \mathrm{mM} \mathrm{Ca}\left(\mathrm{NO}_{3}\right)_{2}$. Plants were then transferred for $8 \mathrm{~d}$ onto a layer of each preincubated soil sample $(6 \mathrm{~mm}$ thick, equivalent to $9 \mathrm{~g}$ dry mass, with a density of $\left.1.2 \mathrm{~g} / \mathrm{cm}^{3}\right)$, but a polyamide mesh $(30 \mu \mathrm{m}$ pore size) separated the roots from the soil. During soil-plant contact, a nutrient solution (same composition as previously described) connected to the soil layer via filter paper wicks (grade 541; Whatman) supplied the plants with major nutrients. During soil-plant contact, soil moisture thus increased up to $100 \%$ water holding capacity. After $8 \mathrm{~d}$, the soil layer in contact with roots was considered a rhizosphere. Preincubated bulk soil samples were also incubated for $8 \mathrm{~d}$ in RHIZOtest devices without plants. The whole experiment was replicated 4 times successively (i.e., experiments 1-4) in similar conditions. In each experiment, 3 soil samples (18, 29, and 47) were replicated 3 times. The present study was focused on the bulk soil results (hereafter referred to as "soil results"); the plant-rhizosphere results will be discussed elsewhere.

The soil solution data analysis (see the section Extraction and analysis of soil solutions) using the Wilcoxon test for matched samples (Statistica, Ver 6; StatSoft) showed that the 4 experiments were significantly $(p<0.05)$ different from each other (Supplemental Data, Table S3). Data from the 4 experiments were consequently analyzed independently and not averaged. The results obtained in the 4 experiments are discussed in the text; for brevity, however, only data from experiment 1 are presented in the tables and figures. Data from experiments 2, 3, and 4 are presented as Supplemental Data.

Table 1. Physicochemical properties of the 55 soil samples $^{\mathrm{a}}$

\begin{tabular}{|c|c|c|c|c|c|c|c|c|c|c|}
\hline & $\begin{array}{c}\text { Clay }^{\mathrm{b}} \\
(\%)\end{array}$ & $\begin{array}{l}\text { Silt }^{\mathrm{b}} \\
(\%)\end{array}$ & $\mathrm{pH}-\mathrm{H}_{2} \mathrm{O}^{\mathrm{c}}$ & $\begin{array}{c}\mathrm{CaCO}_{3}{ }^{\mathrm{d}} \\
(\%)\end{array}$ & $\underset{(\%)}{\text { Organic } C^{\mathrm{e}}}$ & $\underset{\mathrm{C} / \mathrm{N}^{\mathrm{e}, \mathrm{f}}}{\text { Organic }}$ & $\begin{array}{c}\mathrm{CEC}^{\mathrm{g}} \\
(\mathrm{cmol} / \mathrm{kg})\end{array}$ & $\begin{array}{c}\text { Fe oxides }{ }^{\mathrm{h}} \\
(\mathrm{g} / \mathrm{kg})\end{array}$ & $\begin{array}{l}\text { Al oxides }{ }^{\mathrm{h}} \\
\text { (g/kg) }\end{array}$ & $\begin{array}{r}\text { Total } \mathrm{Cu} \\
(\mathrm{mg} / \mathrm{kg})\end{array}$ \\
\hline Minimum & 3 & 3 & 4.4 & 0.0 & 0.1 & 0.9 & 0.1 & 5 & 2 & 6 \\
\hline Quartile 1 & 9 & 17 & 5.8 & 0.1 & 1.3 & 1.1 & 5.2 & 22 & 11 & 22 \\
\hline Median & 15 & 34 & 6.4 & 0.4 & 2.3 & 1.3 & 10.2 & 41 & 15 & 28 \\
\hline Mean & 17 & 34 & 6.5 & 2.4 & 2.6 & 1.4 & 13.2 & 56 & 33 & 105 \\
\hline Quartile 3 & 22 & 46 & 7.3 & 1.7 & 3.4 & 1.5 & 18.9 & 75 & 23 & 99 \\
\hline Maximum & 53 & 75 & 8.2 & 22.1 & 12.6 & 3.1 & 73.8 & 205 & 167 & 1100 \\
\hline
\end{tabular}

${ }^{\mathrm{a}} n=55$, except for $\mathrm{CaCO}_{3}$, for which $n=14$.

${ }^{\mathrm{b}}$ According to the Association Française de Normalisation [39].

${ }^{\mathrm{c}}$ According to the International Organization for Standardization [40].

${ }^{\mathrm{d}}$ According to the International Organization for Standardization [41].

eAccording to the International Organization for Standardization [42].

${ }^{\mathrm{f}}$ According to the International Organization for Standardization [43].

${ }^{\mathrm{g}}$ According to the Association Française de Normalisation [44].

${ }^{\mathrm{h}}$ Extracted with $\left(\mathrm{NH}_{4}\right)_{2} \mathrm{C}_{2} \mathrm{O}_{4}$ at $\mathrm{pH} 3$ according to Tamm [45].

${ }^{\mathrm{i}}$ According to the International Organization for Standardization [46].

$\mathrm{CEC}=$ cation exchange capacity. 


\section{Extraction and analysis of soil solutions}

After $14+8 \mathrm{~d}$ of soil incubation with the nutrient solution (composition given in the section Soil characteristics and incubation), the soil solution was considered to be in equilibrium with the nutrient solution composition [28]. At harvest, each of the 55 moist soil samples was stirred for $2 \mathrm{~h}$ with the nutrient solution (dry soil, 1:10 nutrient solution ratio). The mixture of soil sample and nutrient solution was then centrifuged at $5000 \mathrm{~g}$ for $10 \mathrm{~min}$ and the supernatant was filtered at $0.22 \mu \mathrm{m}$ with cellulose acetate filters prerinsed with ultrapure water. The first milliliter of filtrate was discarded. The soil solutions obtained were subdivided. Subsamples were stabilized with either $1 \mathrm{mM} \mathrm{NaN}_{3}$ or $\mathrm{HNO}_{3} 2.5 \%$ (v/v) and finally stored at $4{ }^{\circ} \mathrm{C}$ until subsequent analysis.

Free $\mathrm{Cu}$ activity was measured using a $\mathrm{Cu}$-selective electrode (Thermo Scientific Orion; 9629BNWP). The electrode was calibrated on a daily basis within the 13.0 to 4.9 range of $\mathrm{pCu}^{2+}$ in $\mathrm{Cu}$ solutions buffered with iminodiacetic acid, as detailed elsewhere $[29,30]$. The calibration curve showed a $95 \%$ slope efficiency compared with the theoretical Nerstian slope $\left(r^{2}=0.997, n=100\right)$. The $\mathrm{pH}$ was measured using a combined electrode (Mettler Toledo; InLab 418). In addition to calibration, the quality of $\mathrm{pH}$ and $\mathrm{pCu}^{2+}$ measurements was validated by repeating in each daily series a sample from the previous analytical series. Dissolved organic carbon (DOC) was determined using a carbon analyzer in nonpurgeable organic carbon mode (TOC-L; Shimadzu). Samples were bubbled for $90 \mathrm{~s}$ with $1.5 \% \mathrm{HCl}$ to eliminate carbonates before injection into the oven $\left(680^{\circ} \mathrm{C}\right)$. The quality of DOC measurements was validated using the certified reference material Missippi-03 that was recovered within $105 \pm 12 \%$. Total $\mathrm{Cd}, \mathrm{Cr}, \mathrm{Cu}, \mathrm{Ni}, \mathrm{Pb}$, and $\mathrm{Zn}$ concentrations were determined by inductively coupled plasma-mass spectrometry (ICP-MS; Q-ICP-MS X Series II + CCTTM; Thermo Fischer). The quality of ICP-MS measurements was validated using the certified reference material SLRS-5. Concentrations of $\mathrm{Ca}, \mathrm{Mg}, \mathrm{K}$, and $\mathrm{Na}$ were determined by ICP-atomic emission spectroscopy (Vista pro model; Varian). Concentrations of $\mathrm{NH}_{4}^{+}$and $\mathrm{Cl}^{-}$were determined by colorimetry (model Evolution II; Alliance). Concentrations of $\mathrm{NO}_{3}{ }^{-}$and $\mathrm{SO}_{4}{ }^{2-}$ were determined by ion chromatography (DX-600; Dionex). All analytical determination findings are given as Supplemental Data (Table S4).

\section{Modeling free $\mathrm{Cu}$ activity}

Free $\mathrm{Cu}$ activity in soil solutions was predicted using WHAM (version VII), which was designed to simulate the competitive binding of proton and metal cations on fulvic and humic acids [31]. We used WHAM to assess the impact of the default settings on the prediction of $\mathrm{pCu}^{2+}$ in solution. The input parameters were the concentrations of major cations $(\mathrm{Ca}, \mathrm{Mg}$, $\mathrm{Na}, \mathrm{K}$, and $\left.\mathrm{NH}_{4}{ }^{+}\right)$and anions $\left(\mathrm{Cl}^{-}, \mathrm{NO}_{3}{ }^{-}\right.$, and $\left.\mathrm{SO}_{4}{ }^{2-}\right)$; total $\mathrm{Cu}$, $\mathrm{Cd}, \mathrm{Zn}, \mathrm{Pb}, \mathrm{Ni}$, and $\mathrm{Cr}$ concentrations; $\mathrm{Al}^{3+}$ and $\mathrm{Fe}^{3+}$ activities; concentration of DOM reactive toward metal cations; $\mathrm{pH} ; \mathrm{CO}_{2}$ partial pressure (arbitrarily assigned at $10^{-3.5} \mathrm{~atm}$ ); and temperature $\left(25^{\circ} \mathrm{C}\right)$. Free $\mathrm{Al}$ and $\mathrm{Fe}$ activities were calculated as commonly done by assuming their equilibrium with $\mathrm{Fe}(\mathrm{OH})_{3}$ and $\mathrm{Al}(\mathrm{OH})_{3}$ with solubility products $\left(\log K_{\mathrm{s}}\right)$ of 2.7 and 8.5, respectively [20]. The binding properties of DOM toward proton and metal cations were simulated by using the reference fulvic acid defined by default in WHAM [31]. In WHAM, the $\mathrm{Cu}$ binding constant for type A sites of fulvic acid $\left(\log K_{\mathrm{Cu}}\right)$ is set at 2.16 and used to calculate the $\mathrm{Cu}$ binding constant for type B sites (see Tipping et al. [31] for rationale). In the absence of information on the DOC/DOM ratio, the default option consisted of calculating the concentration of DOM from DOC based on the assumption that DOM contained 50\% of C [14]. The concentration of DOM reactive toward metal cations was determined by multiplying the DOM concentration by $\%$ r-DOM. Free $\mathrm{Cu}$ activity was calculated with WHAM by using the default settings defined above, as is commonly done in predictive ecotoxicology, or by adjusting \% r-DOM, $\log K_{\mathrm{Cu}}$, $\log K_{\mathrm{sFe}}$, or $\log K_{\mathrm{sAl}}$ for each soil to neatly fit the measured $\mathrm{pCu}^{2+}$. The deviation between measured and predicted $\mathrm{pCu}^{2+}$ was determined by calculating the root mean square residual. The uncertainty in predicted $\mathrm{pCu}^{2+}$ resulting from analytical uncertainties in $\mathrm{pH}( \pm 0.3)$, total $\mathrm{Cu}$ concentration $( \pm 1.3 \%)$, and DOM concentration $( \pm 12.3 \%)$ was calculated using the Monte Carlo procedure (1999 samples) included in WHAM. The analytical uncertainties were determined by calculating the standard deviation on calibration standards and certified material. Sensitivity analyses were performed to determine the impact of the variability of $\log K_{\mathrm{Cu}}, \log K_{\mathrm{sFe}}$, and $\log K_{\mathrm{sAl}}$ on $\mathrm{pCu}^{2+}$ predicted with WHAM.

\section{Modeling $\mathrm{Cu}$ toxicity on soil organisms}

The free ion effective dose model was developed and parameterized to estimate the $\mathrm{Cu}$ toxicity at 3 soil organism levels: microorganisms, invertebrates, and higher plants [3]. Seven toxicological endpoints were thus targeted, which included the inhibition of potential nitrification, maize residue mineralization, glucose-induced respiration, the reproduction of Folsomia candida and Eisenia fetida, and the growth of Hordeum vulgare roots and L. esculentum shoots. The free ion effective dose model was described in detail by Lofts et al. [3]. Briefly, the toxic response $(R)$ of soil organisms $(R=100$, no toxic effect; $R=50$ and 0 , toxic effect equivalent to a $50 \%$ and $100 \%$ reduction in the biological endpoint, respectively) was calculated from the effective dose of toxicant in soil, which in turn was calculated from the $\mathrm{Cu}^{2+}$ concentration and $\mathrm{pH}$ in soil solution. A specific equation was used for each toxicological endpoint according to model $2 \mathrm{~b}$ proposed by Lofts et al. [3].

We used the free ion effective dose model to theoretically assess the impact on $R$ of the default settings defined in WHAM and used to predict $\mathrm{Cu}$ speciation in soil solution. The $R$ values for the 7 toxicological endpoints were calculated for the 55 soil solutions from the $\mathrm{pH}$ and $\mathrm{Cu}^{2+}$ concentration. The $\mathrm{Cu}^{2+}$ concentration was calculated from $\mathrm{pCu}^{2+}$ measured or predicted with WHAM by using the default settings, as is commonly done in predictive ecotoxicology. The $R$ deviation estimated from the predicted $\mathrm{Cu}^{2+}$ was compared with the $R$ estimated from measured $\mathrm{Cu}^{2+}$ by calculating the root mean square residual.

\section{RESULTS AND DISCUSSION}

\section{Wide variation in soil solution chemical properties}

Although significant differences were noted between some of the 4 replicated experiments (Supplemental Data, Table S3) regarding the 4 main parameters (i.e., $\mathrm{pH}$, total copper concentration $\left[\mathrm{pCu}_{\mathrm{T}}\right], \mathrm{pCu}^{2+}$, and DOM concentration) measured in the 55 soil solutions, the similarity of the trend exhibited between each replication of these 4 parameters was checked by assessing the correlations between each experiment and the mean values of the 4 experiments (Supplemental Data, Figure $\mathrm{S} 1$ and Tables S5 and S7). The $\mathrm{pH}, \mathrm{pCu}_{\mathrm{T}}$, and $\mathrm{pCu}^{2+}$ values for the 55 soil solutions of each experiment were very well correlated $\left(r^{2}\right.$ adj $\left.\geq 0.91\right)$ with the mean values of the 4 


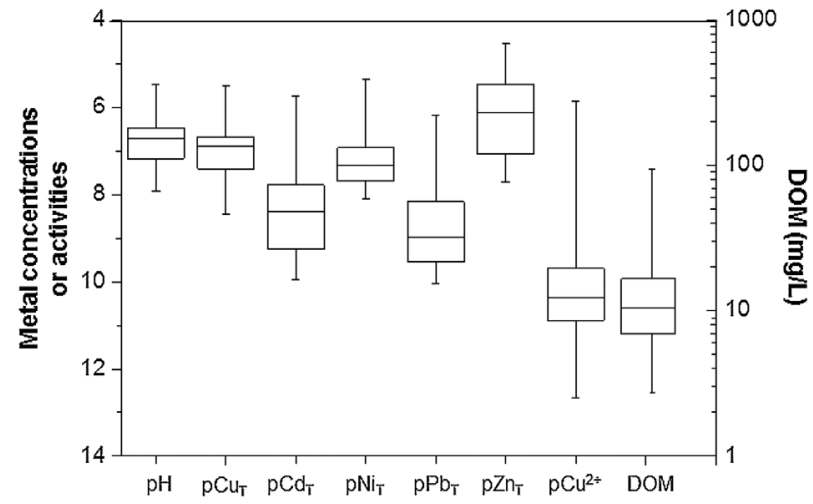

Figure 1. Metal and dissolved organic matter (DOM) concentrations, $\mathrm{pH}$, and $\mathrm{Cu}^{2+}$ activities $\left(\mathrm{pCu}^{2+}\right)$ measured in the 55 soil solutions of experiment 1. The values represented from the bottom to the top indicate the minimum, first quartile, median, third quartile, and maximum values. $\mathrm{pCd}_{\mathrm{T}}=$ total cadmium concentration; $\mathrm{pCu}_{\mathrm{T}}=$ total copper concentration; $\mathrm{pNi}_{\mathrm{T}}=$ total nickel concentration; $\mathrm{pPb}_{\mathrm{T}}=$ total lead concentration; $\mathrm{pZn}_{\mathrm{T}}=$ total zinc concentration.

experiments, with a relative standard deviation of $<4.2 \%$, $<5.1 \%$, and $<12.5 \%$, respectively. Considering that the DOM concentration only varied over 1 order of magnitude, the DOM concentration values (expressed as $\log _{10}$ ) for the 55 soil solutions of each experiment were reasonably well correlated $\left(0.51 \leq r^{2}{ }_{\text {adj }} \leq 0.79\right)$ with the mean values of the 4 experiments and exhibited a relative standard deviation of $<33.8 \%$.

The chemical properties of the solutions extracted from the 55 soil samples varied widely in the 4 experiments (Figure 1; Supplemental Data, Figure S3). In experiment 1, for instance, the DOM concentration ranged from $2.7 \mathrm{mg} / \mathrm{L}$ to $94 \mathrm{mg} / \mathrm{L}$, while the $\mathrm{pH}$ ranged from 5.5 to 7.9 and the total dissolved $\mathrm{Cu}, \mathrm{Pb}$, $\mathrm{Ni}, \mathrm{Zn}$, and $\mathrm{Cd}$ concentration ranged from $10^{-10}$ to $10^{-4.5} \mathrm{M}$, respectively. Accordingly, $\mathrm{pCu}^{2+}$ varied over 7 orders of magnitude, from 12.7 to 5.9. The $\mathrm{Cu}^{2+}$-to-total $\mathrm{Cu}$ concentration ratio ranged from $0.01 \%$ to $44 \%$, which means that $\mathrm{pCu}^{2+}$ was not solely dependent on the $\mathrm{pCu}_{\mathrm{T}}$ variation. Our data set encompassed the variability in chemical parameters commonly found in the soil solution [18,32] and was therefore relevant for assessing the impact of reactive DOM on $\mathrm{Cu}$ speciation in solution and the ecotoxicity in soil.

\section{Default WHAM parameterization skews the prediction of $\mathrm{Cu}$ speciation in soil solution}

Default WHAM parameterization substantially skewed the prediction of measured $\mathrm{pCu}^{2+}$, with the root mean square residual ranging from 0.8 to 1.3 in the 4 experiments (Figure 2; Supplemental Data, Figures S4-S6, panel a). Considering that the measured $\mathrm{pCu}^{2+}$ varied widely (i.e., over approximately 7 orders of magnitude), the predicted $\mathrm{pCu}^{2+}$ with the default WHAM parameterization was poorly correlated with the measured $\mathrm{pCu}^{2+}\left(r^{2}{ }_{\text {adj }}=0.61-0.73\right)$. The maximal deviation between predicted and measured $\mathrm{pCu}^{2+}$ was $2.7 \mathrm{pCu}^{2+}$ units, $2.5 \mathrm{pCu}^{2+}$ units, $1.8 \mathrm{pCu}^{2+}$ units, and $2.1 \mathrm{pCu}^{2+}$ units in experiments $1,2,3$, and 4 , respectively. The measured $\mathrm{pCu}^{2+}$ was mainly overestimated in experiments 1 and 2 , and it was mainly underestimated in experiments 3 and 4 .

The uncertainty in predicted $\mathrm{pCu}^{2+}$ as a result of analytical uncertainties in the measured $\mathrm{pH}, \mathrm{pCu}_{\mathrm{T}}$, and the $\mathrm{DOM}$ concentration used as input data in WHAM ranged from $0.32 \mathrm{pCu}^{2+}$ units to $0.90 \mathrm{pCu}^{2+}$ units in the 4 experiments (Figure 2; Supplemental Data, Figures S4-S6, panel a). These analytical uncertainties do not fully explain the discrepancy observed between the predicted and measured $\mathrm{pCu}^{2+}$ when WHAM was parameterized by default. The present results thus showed that parameterizing WHAM with default values, including \% r-DOM set at $65 \%$ (as is common practice in predictive ecotoxicology), substantially skewed the prediction of the actual $\mathrm{Cu}$ speciation in soil solution, particularly when the investigated soil solutions exhibited a very broad range of chemical properties.

\section{Default WHAM parameterization skews the prediction of $\mathrm{Cu}$ ecotoxicity in soil}

In the 4 experiments, the toxic response $(R)$ to $\mathrm{Cu}$ estimated from the default WHAM parameterization deviated by up to $59 \%, 45 \%$, and $36 \%$ for plants (H. vulgare and L. esculentum),
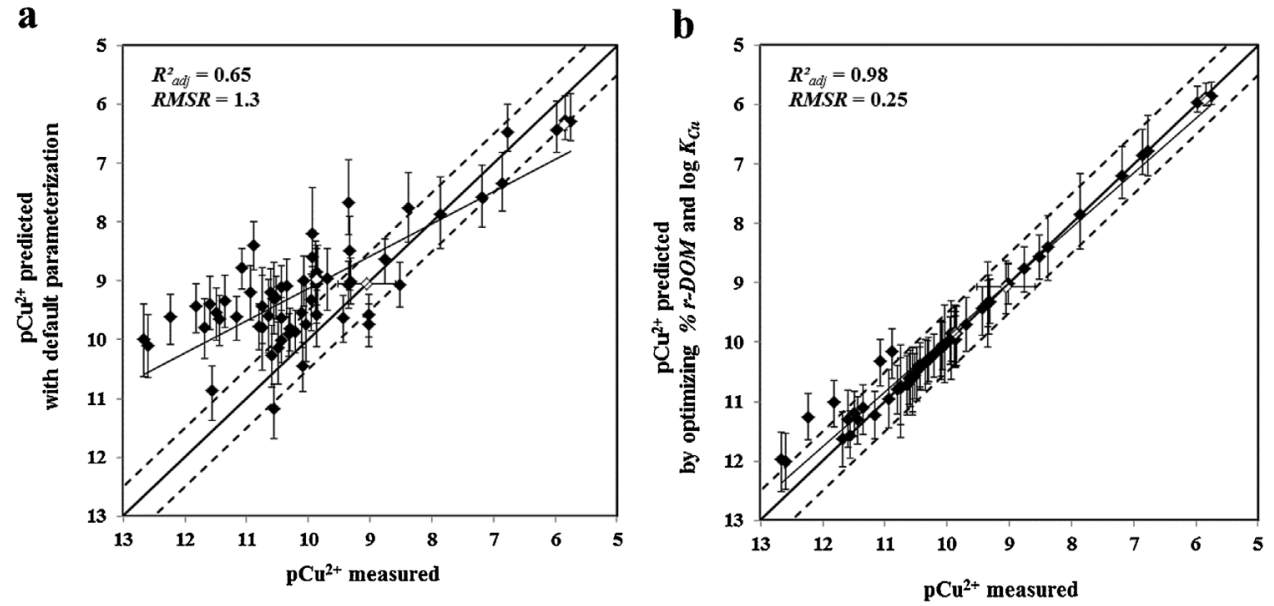

Figure 2. Free $\mathrm{Cu}$ activity $\left(\mathrm{pCu}^{2+}\right)$ predicted with the Windermere humic aqueous model VII (WHAM VII) as a function of the measured $\mathrm{pCu}{ }^{2+}$ in the 55 soil solutions of experiment 1 . Free Cu activity was predicted with WHAM VII using either (a) a single default value for the percentage of dissolved organic matter reactive toward metal cations ( $\% \mathrm{r}-\mathrm{DOM}=65 \%$ ), the $\mathrm{Cu}$ binding constant of reactive dissolved organic matter $\left(\mathrm{DOM} ; \log K_{\mathrm{Cu}}=2.16\right)$, and the solubility constants of $\mathrm{Fe}(\mathrm{OH})_{3}\left(\log K_{\mathrm{SFe}}=2.7\right)$ and $\mathrm{Al}(\mathrm{OH})_{3}\left(\log K_{\mathrm{SAl}}=8.5\right)$ for all solutions, or $(\mathbf{b})$ an optimized $\%$ r-DOM and $\log K_{\mathrm{Cu}}$ value within a range restricted to physically meaningful values for each soil solution. Vertical error bars represent the $95 \%$ confidence interval of pCu ${ }^{2+}$ predicted with WHAM VII when considering the analytical uncertainty on $\mathrm{pH}$ and total $\mathrm{Cu}$ and DOM concentrations (see Materials and Methods for rationale). Empty data points represent soil samples 18, 29, and 47 that were replicated thrice with their standard deviation as a horizontal error bar. The thin solid line represents the regression line. The thick solid line represents the 1:1 line. Dashed lines represent the $1: 1$ line $\pm 0.5 \mathrm{pCu}^{2+}$ unit. $r_{\text {adj }}^{2}=$ adjusted $r^{2}$; RMSR $=$ root mean square residual. 
invertebrates ( $F$. candida and $E$. fetida), and microbial functions (potential nitrification, maize residue mineralization, and glucose-induced respiration), respectively, from $R$ estimated from the measured $\mathrm{pCu}^{2+}$ (Figure 3; Supplemental Data, Figures S7-S9, panels a, c, and e). These results showed that parameterizing WHAM by default, as is common practice in predictive ecotoxicology, substantially skewed the estimation of $\mathrm{Cu}$ ecotoxicity in soil, which was a result of the skewed prediction of the actual $\mathrm{Cu}$ speciation in soil solution.
The $R$ deviation between the default WHAM parameterization and the measured values showed the same trend as the sensitivity of soil organisms to Cu toxicity: plants $>$ invertebrates $>$ microbial functions. According to free ion effective dose parametrization [3], the concentration causing a 50\% effect (EC50) increases in the following order: plants $<$ invertebrates $<$ microbial functions. This suggests that $\mathrm{Cu}$ toxicity has a greater impact on plants than on invertebrates and microbial functions. In the 4 experiments (Figure 3; Supplemental Data, Figures S7-S9,
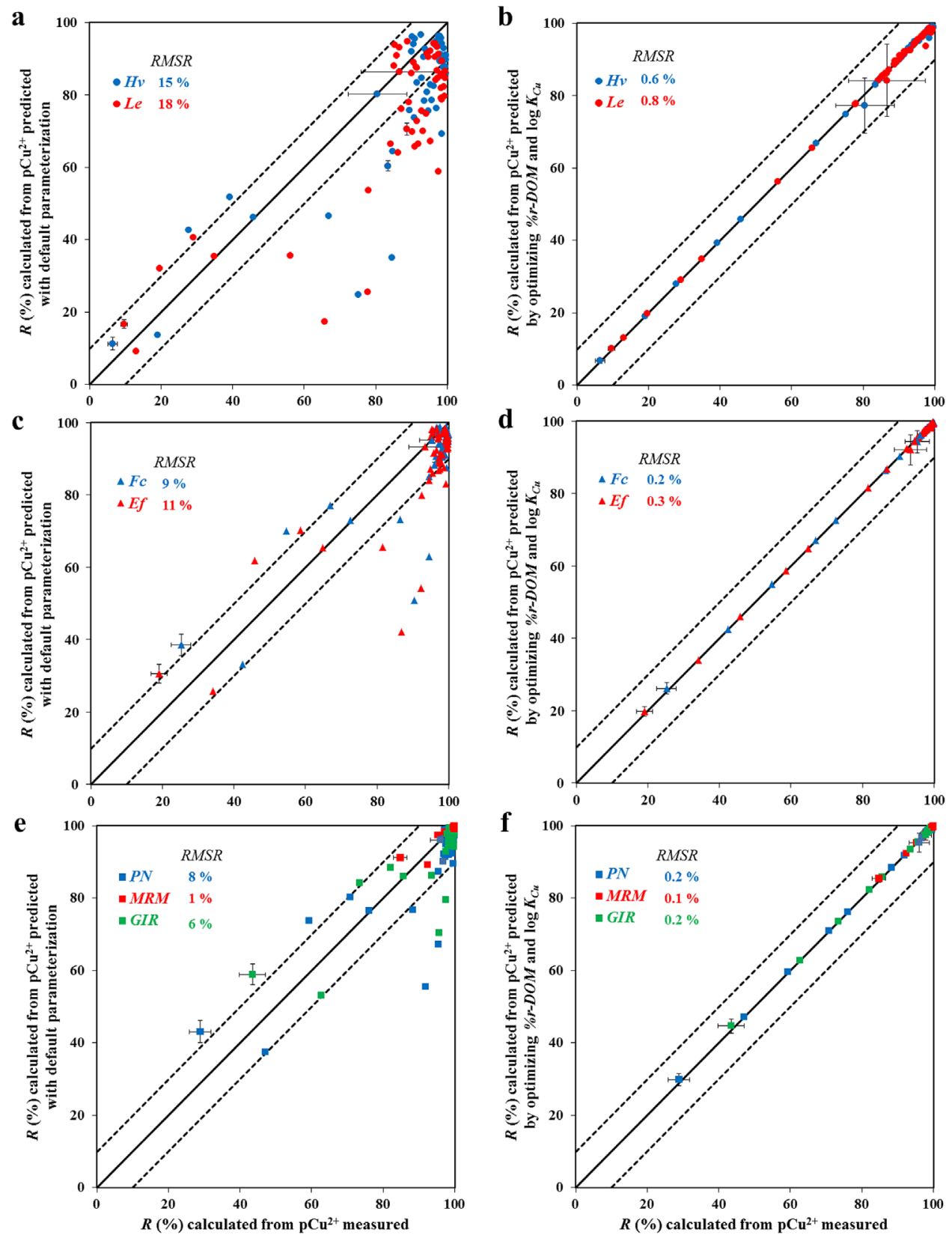

Figure 3. Toxic response $(R)$ of plants $(\mathbf{a}, \mathbf{b})$, invertebrates $(\mathbf{c}, \mathbf{d})$, and microbial functions $(\mathbf{e}, \mathbf{f})$ calculated with the free ion effective dose model from free Cu activity $\left(\mathrm{pCu}^{2+}\right.$ ) predicted with the Windermere humic aqueous model VII (WHAM VII) ( $y$ axis) or measured ( $x$ axis) in the 55 soil solutions of experiment 1. The toxic endpoints are the growth of Hordeum vulgare roots ( $\mathrm{H} v$; blue circles) and Lycopersicon esculentum shoots (Le; red circles) for plants; the reproduction of Folsomia candida ( $F c$; blue triangles) and Eisenia fetida (Ef; red triangles) for invertebrates; and the inhibition of potential nitrification (PN; blue squares), maize residue mineralization (MRM; red squares), and glucose-induced respiration (GIR; green squares) for microbial functions. $\mathrm{R}$ values of 100 and 0 represent the minimal and maximal $\mathrm{Cu}$ toxicity, respectively. Free $\mathrm{Cu}$ activity was predicted with WHAM VII by using either (a,c,e) a single default value for the percentage of dissolved organic matter reactive toward metal cations $(=65 \%)$, the Cu binding constant of reactive DOM $\left(\log \mathrm{K}_{\mathrm{Cu}}=2.16\right)$, and the solubility constants of $\mathrm{Fe}(\mathrm{OH})_{3}\left(\log \mathrm{K}_{\mathrm{sFe}}=2.7\right)$ and $\mathrm{Al}(\mathrm{OH})_{3}\left(\log \mathrm{K}_{\mathrm{sAl}}=8.5\right)$ for all solutions, or $(\mathrm{b}, \mathrm{d}, \mathrm{f})$ an optimized $\% \mathrm{r}-\mathrm{DOM}$ and log $\mathrm{K}_{\mathrm{Cu}}$ value within a range restricted to physically meaningful values for each soil solution. Error bars represent the standard deviation $(n=3)$ for soil samples 18,29 , and 47 . Solid line represents the 1:1 line. Dashed lines represent the 1:1 line $\pm 10 \% . \mathrm{DOM}=$ dissolved organic matter; $\% \mathrm{r}-\mathrm{DOM}=$ percentage of dissolved organic matter reactive toward metal cations; RMSR = root mean square residual. 
panels a, c, and e), the root mean square residual of $R$ ranged from $10 \%$ to $18 \%$ for plant growth $(H$. vulgare and $L$. esculentum combined), from $7 \%$ to $11 \%$ for invertebrate reproduction ( $F$. candida and E. fetida combined), and from $1 \%$ to $9 \%$ for microbial functions (potential nitrification, maize residue mineralization, and glucose-induced respiration combined). An $R$ deviation of $>10 \%$ between the default WHAM parameterization and the measured values was observed for $39 \%$ of the data points for plant growth (H. vulgare and L. esculentum combined), $16 \%$ of the data points for invertebrate reproduction $(F$. candida and $E$. fetida combined), and $8 \%$ of the data points for microbial functions (potential nitrification, maize residue mineralization, and glucose-induced respiration combined). This indicated that the $R$ deviation between the default and measured values increased at a given level of $\mathrm{Cu}$ exposure with the sensitivity of soil organisms to $\mathrm{Cu}$ toxicity.

The $R$ deviation between the default WHAM parameterization and the measured values tended to be maximal at approximately a $50 \% R$ value but tended to be minimal for $R$ higher than approximately $80 \%$ and lower than approximately $20 \%$ for the 7 toxicological endpoints (Figure 3; Supplemental Data, Figures S7-S9, panels a, c, and e). This was directly related to the log-logistic dose-response relationship used in the free ion effective dose model to predict toxicological responses. Because of the sigmoidal shape of this relationship, the slope coefficient is highest at a $50 \% R$ value and tends to be 0 when $R$ is $0 \%$ and $100 \%$ [33]. Accordingly, skewed prediction of $\mathrm{Cu}$ speciation in soil solution in a $\mathrm{pCu}^{2+}$ range close to the effective concentration causing an effect close to $0 \%$ or $100 \%$, such as the widely used $10 \%$ effect concentration, would have less impact on the toxic response prediction. However, skewed prediction of $\mathrm{Cu}$ speciation in soil solution in a $\mathrm{pCu}^{2+}$ range close to the EC50 would result in a high deviation in the toxic response prediction. Considering the widespread use of EC50 in predictive ecotoxicology, we feel that it is critical to optimize the default WHAM parameterization by including the optimization of $\%$ r-DOM when calculating $\mathrm{Cu}$ speciation in soil solution to avoid substantial deviation in the prediction of toxic effects on soil organisms.
Heterogeneity in DOM binding properties drives the prediction of $\mathrm{Cu}$ solution speciation and ecotoxicity in soil

The prediction of $\mathrm{pCu}^{2+}$ with WHAM parameterized by optimizing the $\% \mathrm{r}$-DOM in an unrestricted range, while setting the $\log K_{\mathrm{Cu}}, \log K_{\mathrm{sFe}}$, and $\log K_{\mathrm{sAl}}$ at their default values, neatly fitted the $\mathrm{pCu}^{2+}$ measured with a root mean square residual $<0.03$ (Table 2; Supplemental Data, Tables S9-S11). In comparison, the prediction of $\mathrm{pCu}^{2+}$ with WHAM parameterized by optimizing $\log K_{\mathrm{Cu}}, \log K_{\mathrm{sFe}}$, or $\log K_{\mathrm{sAl}}$ in an unrestricted range, while setting the other parameters at their default values, less adequately fitted the $\mathrm{pCu}^{2+}$ measured than when WHAM was parameterized by optimizing the \% r-DOM, as the root mean square residual values were $<0.25,1.09$, and 1.24 , respectively. The optimized $\%$ r-DOM values (expressed as $\log _{10}$ ) for the 55 soil solutions of each experiment were closely correlated $\left(0.78 \leq r^{2}\right.$ adj $\left.\leq 0.83\right)$ with the mean values of the 4 experiments (Supplemental Data, Figure S2 and Tables S6 and S8). In comparison, the optimized $\log K_{\mathrm{Cu}}, \log K_{\mathrm{sFe}}$, and $\log$ $K_{\mathrm{sAl}}$ values for the 55 soil solutions of each experiment were much less correlated with the mean values of the 4 experiments $\left(0.39 \leq r^{2}\right.$ adj $\left.\leq 0.75\right)$ than was observed for the optimized \% rDOM values. These results suggest that the most efficient and robust option to parameterize WHAM to neatly predict $\mathrm{Cu}$ speciation is to optimize the $\%$ r-DOM for each soil solution without restriction.

However, WHAM parameterization by optimizing the \% r-DOM, $\log K_{\mathrm{Cu}}, \log K_{\mathrm{sFe}}$, or $\log K_{\mathrm{sAl}}$ in an unrestricted range caused these 4 parameters to vary systematically over unrealistic ranges of variation, from $0 \%$ to $7550 \%$ for $\%$ r-DOM, from -2.43 to 2.92 for $\log K_{\mathrm{Cu}}$, from -7.3 to 14.2 for $\log$ $K_{\mathrm{sFe}}$, and from 1.3 to 28.3 for $\log K_{\mathrm{sAl}}$ (Table 2; Supplemental Data, Tables S9-S11). Considering the charge density (sum of carboxyl and phenolic sites ranged $2.7-16.8 \mathrm{mmol}_{+} / \mathrm{g}$ ) reported for 401 DOM samples, including standard and reference fulvic acid, humic acid, and natural organic matter [34] and the charge density of the default fulvic acid in WHAM $\left(7.8 \mathrm{mmol}_{+} / \mathrm{g}\right)$, physically meaningful \% r-DOM values should range from $35 \%$ to $215 \%$. Considering the 32 data sets regarding $\mathrm{Cu}$

Table 2. Deviation calculated as the root mean square residual between measured and predicted free $\mathrm{Cu}^{2+}$ activities $\left(\mathrm{pCu} \mathrm{u}^{2+}\right.$ ) in the $55 \mathrm{soil} \mathrm{solutions}$ of experiment $1^{\mathrm{a}}$

\begin{tabular}{|c|c|c|c|c|c|c|}
\hline & \multicolumn{2}{|c|}{$\mathrm{pCu}^{2+}$ predicted by default ${ }^{\mathrm{b}}$} & \multicolumn{2}{|c|}{$\begin{array}{c}\mathrm{pCu}^{2+} \text { predicted with unrestricted } \\
\text { optimization }\end{array}$} & \multicolumn{2}{|c|}{$\begin{array}{c}\mathrm{pCu}^{2+} \text { predicted with restricted } \\
\text { optimization }\end{array}$} \\
\hline & Parameters & $\mathrm{pCu}^{2+} \mathrm{RMSR}$ & Parameters & $\mathrm{pCu}^{2+} \mathrm{RMSR}$ & Parameters & $\mathrm{pCu}^{2+} \mathrm{RMSR}$ \\
\hline$\%$ r-DOM & 65 & 1.25 & 0.8 to 7550 & 0.002 & 35 to $215^{\mathrm{e}}$ & 0.73 \\
\hline $\log K_{\mathrm{Cu}}$ & 2.16 & & $\leq-1.33$ to 2.92 & 0.05 & 1.84 to $2.46^{\mathrm{f}}$ & 0.59 \\
\hline $\log K_{\mathrm{sFe}}$ & 2.7 & & $\leq-6.3$ to 14.2 & 1.09 & 2.5 to $5^{\mathrm{g}}$ & 1.21 \\
\hline $\log K_{\mathrm{sA} 1}$ & 8.5 & & $\leq 1.3$ to 16.4 & 1.24 & 8.0 to $9.0^{\mathrm{h}}$ & 1.24 \\
\hline$\%$ r-DOM and $\log K_{\mathrm{Cu}}$ & - & & - & - & 35 to $215^{\mathrm{e}}$ and 1.84 to $2.46^{\mathrm{f}}$ & 0.25 \\
\hline
\end{tabular}

${ }^{a}$ Free $\mathrm{Cu}^{2+}$ activities were predicted with Windermere humic aqueous model VII using either a single, default value for the percentage of dissolved organic matter reactive toward metal cations $(\% \mathrm{r}-\mathrm{DOM})$, the $\mathrm{Cu}$ binding constant of reactive dissolved organic matter $\left(\mathrm{log} K_{\mathrm{Cu}}\right)$, and the solubility constants of $\mathrm{Fe}(\mathrm{OH})_{3}$ $\left(\log K_{\mathrm{sFe}}\right)$ and $\mathrm{Al}(\mathrm{OH})_{3}\left(\log K_{\mathrm{sAl}}\right)$ for all soil solutions, or an optimized value of $\%$ r-DOM, $\log K_{\mathrm{Cu}}$, log $K_{\mathrm{sFe}}$, or $\log K_{\mathrm{sAl}}$ with or without restriction for each soil solution.

${ }^{\mathrm{b}}$ Free $\mathrm{Cu}^{2+}$ was calculated by setting the 4 parameters at the default values given in model VII.

${ }^{c}$ Free $\mathrm{Cu}^{2+}$ was calculated by optimizing a single parameter within an unrestricted range of values, while the 3 other parameters were set at the default values given in model VII.

${ }^{\mathrm{d}}$ Free $\mathrm{Cu}^{2+}$ was calculated by optimizing a single parameter within a range restricted to physically meaningful values, while the 3 other parameters were set at the default values given in model VII.

e According to Richie and Perdue [34].

${ }^{\mathrm{f}}$ According to Tipping [8].

${ }^{g}$ According to Baes and Mesmer [35].

${ }^{\mathrm{h}}$ According to Tipping et al. [36].

$\mathrm{RMSR}=$ root mean square residual 
complexation to fulvic acids reviewed by Tipping when parameterizing WHAM [8], physically meaningful $\log K_{\mathrm{Cu}}$ values should range from 1.84 to 2.34. According to Baes and Mesner [35], Tipping et al. [36], and Nordstrom et al. [37], physically meaningful $\log K_{\mathrm{sFe}}$ and $\log K_{\mathrm{sAl}}$ values should range from 2.5 to 5 and from 8 to 9 , respectively. This highlights the need to look for a more realistic optimization of \% r-DOM, log $K_{\mathrm{Cu}}, \log K_{\mathrm{sFe}}$, and $\log K_{\mathrm{sAl}}$ while improving the ability of WHAM to adequately predict $\mathrm{pCu}^{2+}$.

The WHAM parameterization by optimizing \% r-DOM, log $K_{\mathrm{Cu}}, \log K_{\mathrm{sFe}}$, or $\log K_{\mathrm{sAl}}$ within a range restricted to physically realistic values substantially improved the prediction of measured $\mathrm{pCu}^{2+}$ in comparison with the prediction obtained with default WHAM parameterization (Table 2; Supplemental Data, Tables S9-S11). For the 4 experiments, the root mean square residual calculated between predicted and measured $\mathrm{pCu}^{2+}$ ranged from 0.41 to $0.73,0.28$ to $0.59,0.35$ to 1.21 , and 0.73 to 1.24 when WHAM was parameterized by optimizing \% r-DOM, $\log K_{\mathrm{Cu}}, \log K_{\mathrm{sFe}}$, or $\log K_{\mathrm{sAl}}$, respectively. These WHAM prediction improvements remained, however, inadequate when we optimized 1 parameter at a time. This prompted us to further parameterize WHAM by optimizing 2 parameters simultaneously. The 2 best candidates for this simultaneous optimization were $\%$ r-DOM and $\log K_{\mathrm{Cu}}$, which also correspond to the 2 main parameters describing dissolved organic matter binding properties in WHAM. Moreover, WHAM predictions parameterized by optimizing the \% r-DOM over an unrestricted range, while then modifying the $\log K_{\mathrm{Cu}}, \log K_{\mathrm{sFe}}$, or $\log K_{\mathrm{sAl}}$ values within physically realistic value ranges, showed high sensitivity with $\log K_{\mathrm{Cu}}$, lower sensitivity with $\log$ $K_{\mathrm{sFe}}$, and insensitivity with $\log K_{\mathrm{sAl}}$ (Supplemental Data, Figures S10-S13).

The WHAM parameterization by simultaneously optimizing both the \% r-DOM and $\log K_{\mathrm{Cu}}$ within a range restricted to physically realistic values fitted very well the measured $\mathrm{pCu}^{2+}$ with a root mean square residual less than 0.25 for the 4 experiments (Figure 2; Supplemental Data, Figures S4-S6 panel $\mathrm{b})$. Consequently, the toxic response $(R)$ estimated from the WHAM parameterization by simultaneously optimizing the $\%$ r-DOM and $\log K_{\mathrm{Cu}}$ values for each soil also very well fitted the $R$ estimated from the measured $\mathrm{pCu}^{2+}$ for the 7 endpoints in the 4 experiments, with root mean square residuals always $<6 \%$ (Figure 3; Supplemental Data, Figures S7-S9, panels b, d, and $\mathrm{f}$ ). These results showed that parameterizing WHAM by simultaneously optimizing both the \% r-DOM and log $K_{\mathrm{Cu}}$ within a realistic range of values substantially improved the prediction of $\mathrm{Cu}$ solution speciation and hence $\mathrm{Cu}$ ecotoxicity in soil.

The major shortcoming of the present work is that the DOM binding properties (\% r-DOM and $\log K_{\mathrm{Cu}}$ ) were estimated by model optimization instead of by performing analytical determinations, thus questioning the empirical relevance and the practical application of our conclusions. The next step would be to analytically recover the $\%$ r-DOM and $\log K_{\mathrm{Cu}}$ values in some of the most contrasted soil solutions to check if they would confirm the WHAM predictions. Two analytical approaches seem promising to analytically estimate DOM binding properties in soil solution. The first approach is based on the chemical fractionation of DOM into humic acid, fulvic acid, hydrophilic acid, and hydrophobic neutral organic matter, with the great benefit of directly serving the parameterization of models such as WHAM or NICA-Donnan [13,38]. The second approach is based on ultraviolet absorbance, with the great benefit to be routinely applied to large sets of solution samples [17]. Overall, the present findings underline the need for further analytical investigations of the DOM binding properties to improve the parameterization and optimization procedure for geochemical models used in predictive ecotoxicology.

\section{CONCLUSION}

Parameterizing speciation models such as WHAM with default values, particularly by setting the $\%$ r-DOM at $65 \%$, has become very common practice for predicting metal cation speciation in solution and toxicity on soil organisms. However, the present results led us to conclude that it is critical to account for the real heterogeneity in DOM binding properties, including the $\%$ r-DOM and $\log K_{\mathrm{Cu}}$, when calculating $\mathrm{Cu}$ speciation in soil solution to avoid substantial deviation in the prediction of toxic effects on soil organisms.

In the 55 soil samples we investigated, WHAM parameterization by optimizing the $\%$ r-DOM, $\log K_{\mathrm{Cu}}, \log K_{\mathrm{sFe}}$, or $\log K_{\mathrm{sAl}}$ over an unrestricted range led to much better prediction of measured $\mathrm{pCu}^{2+}$ when optimizing either of the DOM binding properties (\% r-DOM or $\log K_{\mathrm{Cu}}$ ) in comparison with the optimization of either $\log K_{\mathrm{sFe}}$ or $\log K_{\mathrm{sAl}}$. However, unrestricted optimization led to much larger \% r-DOM and $\log K_{\mathrm{Cu}}$ variation ranges than previously reported in the literature. More interestingly, WHAM parameterization by optimizing the 2 DOM binding properties simultaneously within a range restricted to physically realistic values predicted the measured $\mathrm{pCu}^{2+}$ very well and, accordingly, much improved the prediction of $\mathrm{Cu}$ toxicity on soil organisms.

From a regulatory perspective, the present results more generally suggest that the derivation of soil quality limits based on quantitative relationships integrating soil properties should better account for the quality of organic matter as related to its binding properties toward metal cations.

Supplemental Data-The Supplemental Data are available on the Wiley Online Library at DOI: 10.1002/etc.3622.

Acknowledgment-The PhD scholarship of T. Djae was funded by ADEME and CIRAD. The French National Research Agency (ANR) via the NormaRHIZO project (09-CES-01) funded the present study. The authors kindly acknowledge J.P. Ambrosi (CNRS), D. Baize (INRA), L. Denaix (INRA), O. Faure (Université Jean Monnet), C. Jolivet (INRA), M. Mench (INRA), and F. van Oort (INRA) for providing some of the soil samples. The authors thank P. Cazevieille, C. Chevassus-Rosset, L. Lemal, J.-L. Marger, M. Montes, and C. Pradier (CIRAD) for the RHIZOtest experiments and the soil solution extraction and analyses; G. Durrieu (Université de Toulon) for dissolved organic matter analyses; and R. Freydier (CNRS) for ICP-MS analyses.

Data availability —Data, associated metadata, and calculation tools are available from the corresponding author (matthieu.bravin@cirad.fr).

\section{REFERENCES}

1. Parker D, Pedler J. 1997. Reevaluating the free-ion activity model of trace metal availability to higher plants. Plant Soil 196:223-228.

2. Ardestani MM, van Straalen NM, van Gestel CAM. 2014. The relationship between metal toxicity and biotic ligand binding affinities in aquatic and soil organisms: A review. Environ Pollut 195:133-147.

3. Lofts S, Criel P, Janssen CR, Lock K, McGrath SP, Oorts K, Rooney CP, Smolders E, Spurgeon DJ, Svendsen C, Van Eeckhout H, Zhao F-Z 2013. Modelling the effects of copper on soil organisms and processes using the free ion approach: Towards a multi-species toxicity model. Environ Pollut 178:244-253.

4. Wang P, Kinraide TB, Smolders E, Zhou D-M, Menzies NW, Thakali S, Xia W-W, Hao X-Z, Peijnenburg WJGM, Kopittke PM. 2013. An electrostatic model predicting $\mathrm{Cu}$ and $\mathrm{Ni}$ toxicity to microbial processes in soils. Soil Biol Biochem 57:720-730. 
5. Thakali S, Allen HE, Di Toro DM, Ponizovsky AA, Rooney CP, Zhao F-J, McGrath SP, Criel P, Van Eeckhout H, Janssen CR, Oorts K, Smolders E. 2006. Terrestrial biotic ligand model. 2. Application to Ni and $\mathrm{Cu}$ toxicities to plants, invertebrates, and microbes in soil. Environ Sci Technol 40:7094-7100.

6. Zhang H, Young SD. 2005. Characterizing the availability of metals in contaminated soils. II. Soil Use Manage 21:459-467.

7. Dudal Y, Gérard F. 2004. Accounting for natural organic matter in aqueous chemical equilibrium models: A review of the theories and applications. Earth Sci Rev 66:199-216.

8. Tipping E. 1998. Humic ion-binding model VI: An improved description of the interactions of protons and metal ions with humic substances. Aquat Geochem 4:3-47.

9. Milne CJ, Kinniburgh DG, Tipping E. 2001. Generic NICA-Donnan model parameters for proton binding by humic substances. Environ Sci Technol 35:2049-2059.

10. Milne CJ, Kinniburgh DG, van Riemsdijk WH, Tipping E. 2003. Generic NICA-Donnan model parameters for metal-ion binding by humic substances. Environ Sci Technol 37:958-971.

11. Groenenberg JE, Koopmans GF, Comans RNJ. 2010. Uncertainty analysis of the nonideal competitive adsorption-Donnan model: Effects of dissolved organic matter variability on predicted metal speciation in soil solution. Environ Sci Technol 44:1340-1346.

12. Bolan NS, Adriano DC, Kunhikrishnan A, James T, McDowell R, Senesi N. 2011. Dissolved organic matter. Adv Agron 110:1-75.

13. Ren Z-L, Tella M, Bravin MN, Comans RNJ, Dai J, Garnier J-M, Sivry Y, Doelsch E, Straathof A, Benedetti MF. 2015. Effect of dissolved organic matter composition on metal speciation in soil solutions. Chem Geol 398:61-69.

14. Dwane GC, Tipping E. 1998. Testing a humic speciation model by titration of copper-amended natural waters. Environ Int 24:609-616.

15. Bryan SE, Tipping E, Hamilton-Taylor J. 2002. Comparison of measured and modelled copper binding by natural organic matter in freshwaters. Comp Biochem Physiol C Toxicol Pharmacol 133:37-49.

16. De Schamphelaere KAC, Vasconcelos FM, Tack FMG, Allen HE, Janssen CR. 2004. Effect of dissolved organic matter source on acute copper toxicity to Daphnia magna. Environ Toxicol Chem 23:1248-1255.

17. Amery F, Degryse F, Cheyns K, De Troyer I, Mertens J, Merckx R, Smolders E. 2008. The UV-absorbance of dissolved organic matter predicts the fivefold variation in its affinity for mobilizing $\mathrm{Cu}$ in an agricultural soil horizon. Eur J Soil Sci 59:1087-1095.

18. Vulkan R, Zhao FJ, Barbosa-Jefferson V, Preston S, Paton GI, Tipping E, McGrath SP. 2000. Copper speciation and impacts on bacterial biosensors in the pore water of copper-contaminated soils. Environ Sci Technol 34:5115-5121.

19. Weng L, Temminghoff EJM, Lofts S, Tipping E, Van Riemsdijk WH. 2002. Complexation with dissolved organic matter and solubility control of heavy metal in a sandy soil. Environ Sci Technol 36:4804-4810

20. Tipping E, Rieuwerts J, Pan G, Ashmore MR, Lofts S, Hill MTR, Farago ME, Thornton I. 2003. The solid-solution partitioning of heavy metals $(\mathrm{Cu}, \mathrm{Zn}, \mathrm{Cd}, \mathrm{Pb})$ in upland soils of England and Wales. Environ Pollut 125:213-225.

21. Zhao F-J, Rooney CP, Zhang H, McGrath SP. 2006. Comparison of soil solution speciation and diffusive gradients in thin-films measurement as an indicator of copper bioavailability to plants. Environ Toxicol Chem 25:733-742.

22. Micó C, Li HF, Zhao FJ, McGrath SP. 2008. Use of Co speciation and soil properties to explain variation in Co toxicity to root growth of barley (Hordeum vulgare L.) in different soils. Environ Pollut 156:883-890.

23. Qiu H, Vijver MG, van Gestel CAM, He E, Peijnenburg WJGM. 2014. Modeling cadmium and nickel toxicity to earthworms with the free ion approach. Environ Toxicol Chem 33:438-446.

24. Lin Y, Di Toro DM, Allen HE. 2015. Development and validation of a terrestrial biotic ligand model for Ni toxicity to barley root elongation for non-calcareous soils. Environ Pollut 202:41-49.

25. Nolan AL, McLaughlin MJ, Mason SD. 2003. Chemical speciation of $\mathrm{Zn}, \mathrm{Cd}, \mathrm{Cu}$, and $\mathrm{Pb}$ in pore waters of agricultural and contaminated soils using Donnan dialysis. Environ Sci Technol 37:90-98.

26. Bravin MN, Michaud AM, Larabi B, Hinsinger P. 2010. RHIZOtest: A plant-based biotest to account for rhizosphere processes when assessing copper bioavailability. Environ Pollut 158:3330-3337.

27. International Organization for Standardization. 2015. Soil qualityPlant-based test to assess the environmental bioavailability of trace elements to plants. ISO 16198. Geneva, Switzerland.

28. Bravin MN, Garnier C, Lenoble V, Gérard F, Dudal Y, Hinsinger P. 2012. Root-induced changes in $\mathrm{pH}$ and dissolved organic matter binding capacity affect copper dynamic speciation in the rhizosphere. Geochim Cosmochim Acta 84:256-268.

29. Rachou J, Gagnon C, Sauvé S. 2007. Use of an ion-selective electrode for free copper measurements in low salinity and low ionic strength matrices. Environ Chem 4:90.

30. Bravin MN, Martí AL, Clairotte M, Hinsinger P. 2009. Rhizosphere alkalisation-A major driver of copper bioavailability over a broad $\mathrm{pH}$ range in an acidic, copper-contaminated soil. Plant Soil 318:257-268

31. Tipping E, Lofts S, Sonke JE. 2011. Humic ion-binding model VII: A revised parameterisation of cation-binding by humic substances. Environ Chem 8:225.

32. Sauvé S, McBride MB, Norvell WA, Hendershot WH. 1997. Copper solubility and speciation of in situ contaminated soils: Effects of copper level, pH and organic matter. Water Air Soil Pollut 100:133-149.

33. Thakali S, Allen HE, Di Toro DM, Ponizovsky AA, Rooney CP, Zhao F-J, McGrath SP. 2006. A terrestrial biotic ligand model. 1. Development and application to $\mathrm{Cu}$ and $\mathrm{Ni}$ toxicities to barley root elongation in soils. Environ Sci Technol 40:7085-7093.

34. Ritchie JD, Perdue EM. 2003. Proton-binding study of standard and reference fulvic acids, humic acids, and natural organic matter. Geochim Cosmochim Acta 67:85-96.

35. Baes CF, Mesmer RE. 1976. Hydrolysis of Cations. Wiley, New York, NY, USA.

36. Tipping E, Rey-Castro C, Bryan SE, Hamilton-Taylor J. 2002. Al(III) and $\mathrm{Fe}(\mathrm{III})$ binding by humic substances in freshwaters, and implications for trace metal speciation. Geochim Cosmochim Acta 66:3211-3224

37. Nordstrom DK, Plummer LN, Langmuir D, Busenberg E, May HM, Jones BF, Parkhurst DL. 1990. Revised chemical equilibrium data for major water-mineral reactions and their limitations. In Chemical Modeling of Aqueous Systems II. American Chemical Society, Cary, NC, pp 398-413.

38. van Zomeren A, Comans RNJ. 2007. Measurement of humic and fulvic acid concentrations and dissolution properties by a rapid batch procedure. Environ Sci Technol 41:6755-6761.

39. Association Française de Normalisation. 2003. Qualité du sol Détermination de la distribution granulométrique des particules du sol Méthode à la pipette. NF X31-107. Paris, France.

40. International Organization for Standardization. 2005. Soil quality Determination of pH. ISO 10390. Geneva, Switzerland.

41. International Organization for Standardization. 1995. Soil quality Determination of carbonate content - Volumetric method. ISO 10693. Geneva, Switzerland.

42. International Organization for Standardization. 1995. Soil quality Determination of organic and total carbon after dry combustion (elementary analysis). ISO 10694. Geneva, Switzerland.

43. International Organization for Standardization. 1995. Soil quality Determination of total nitrogen content by dry combustion (elementary analysis). ISO 13878. Geneva, Switzerland.

44. Association Française de Normalisation. 1999. Qualité des sols Méthodes chimiques - Détermination de la capacité d'échange cationique (CEC) et des cations extractibles. NF X31-130. Paris, France.

45. Tamm O. 1922. Eine methode zur bestimmung der anorganischen komponente des gelkomplexes im boden. Meddelanden fran Statens Skogsförsöksanstalt 19:385-404.

46. International Organization for Standardization. 1995. Soil quality Extraction of trace elements soluble in aqua regia. ISO 11466. Geneva, Switzerland. 